\title{
Distinct Cognitive and Brain Morphological Features in Healthy Subjects Unaware of Informant-Reported Cognitive Decline
}

\author{
Gonzalo Sánchez-Benavides ${ }^{\mathrm{a}, \mathrm{b}}$, Oriol Grau-Rivera ${ }^{\mathrm{a}}$, Raffaele Cacciaglia ${ }^{\mathrm{a}}$, Marc Suárez-Calvet ${ }^{\mathrm{a}}$, \\ Carles Falcon $^{\mathrm{a}, \mathrm{c}}$, Carolina Minguillon ${ }^{\mathrm{a}, \mathrm{b}}$, Nina Gramunt ${ }^{\mathrm{a}, \mathrm{b}}$, Aleix Sala-Vila ${ }^{\mathrm{d}}$, ALFAstudy ${ }^{\dagger}$, \\ Juan Domingo Gispert ${ }^{\mathrm{a}, \mathrm{c}, \mathrm{e}}$ and José Luis Molinuevo ${ }^{\mathrm{a}, \mathrm{b}, *}$ \\ ${ }^{a}$ Barcelonaßeta Brain Research Center, Pasqual Maragall Foundation, Barcelona, Spain \\ ${ }^{\mathrm{b}}$ CIBER Fragilidad y Envejecimiento Saludable (CIBERFES), Madrid, Spain \\ ${ }^{\mathrm{c}}$ Centro de Investigación Biomédica en Red de Bioingeniería, Biomateriales y Nanomedicina \\ (CIBER-BBN), Madrid, Spain \\ ${ }^{\mathrm{d}}$ CIBER Fisiopatología de la Obesidad y Nutrición (CIBERobn), Instituto de Salud Carlos III (ISCIII), \\ Madrid, Spain \\ ${ }^{\mathrm{e}}$ Universitat Pompeu Fabra, Barcelona, Spain
}

Accepted 16 June 2018

\begin{abstract}
.
Background: Subtle cognitive decline preceding cognitive impairment can be self-perceived, referred to as subjective cognitive decline (SCD), or go unrecognized.

Objective: To study the clinical, cognitive, and structural neuroimaging characteristics of psychometrically normal subjects without self-awareness of cognitive decline (unaware decliners, UD) and to compare them with SCD participants and controls.

Methods: 2,640 participants from the ALFA cohort, 1,899 controls, 173 UD (decline reported by the informant only), and 568 SCD underwent clinical and cognitive explorations. A subset of 530 underwent structural MRI (379 Controls; 43 UD; 108 $\mathrm{SCD}$ ). Linear models adjusting for confounders (age, sex, education, and mood state) were used to assess group differences on cognition and voxel-wise grey matter (GM) volumes.

Results: 6.6\% were UD while 21.5\% SCD. No differences in anxiety and depression were observed between controls and UD, while SCD did $(p<0.01)$. UD showed lower performance in the Memory Binding Test free recall $(p<0.005)$ than controls, but no differences compared to SCD. Right medial frontal and insular increments of GM volumes were observed in UD with respect to controls. Informant report of decline in UD and SCD was associated with lower left hippocampal GM volume but related to memory performance only in UD (rho $=0.46, p=0.002)$.

Conclusions: UD had worse memory performance than controls which correlated with hippocampal GM volume and presented brain volume increments in self-appraisal areas (medial frontal and insula). Individuals unaware of cognitive decline may represent a distinct group at risk for cognitive impairment and support the usefulness of informant-reported cognitive decline.
\end{abstract}

Keywords: Anosognosia, cognition, subjective cognitive decline, unaware decliners, voxel-based morphometry

\footnotetext{
${ }^{\dagger}$ The complete list of collaborators of the ALFA Study can be found in the acknowledgements section.

*Correspondence to: Dr. José Luis Molinuevo, BarcelonaBeta Brain Research Centre - Pasqual Maragall Foundation, C/
}

Wellington 30, 08005 Barcelona, Spain. E-mail: jlmolinuevo@ barcelonabeta.org. 


\section{INTRODUCTION}

Alzheimer's disease (AD) is currently conceived as a long-lasting disease that begins decades before the apparition of the first symptoms [1, 2]. As brain pathology progresses, cognitive decline subtly emerges before the appearance of overt symptoms. By definition, this decline remains under the threshold of cognitive impairment, as measured by standard neuropsychological tests, but can be detected through longitudinal testing or may be self-perceived by the subject $[3,4]$. This subjective perception of cognitive decline (SCD) is an established risk factor for objective cognitive impairment and dementia [5-7] and may trigger medical help seeking, primarily when accompanied by worries [8]. The confirmation of cognitive decline by an informant adds value to the prediction of future cognitive decline [9, 10], and it is recognized as one of the features that increase the risk of developing dementia and the likelihood of being in the preclinical stage of $\mathrm{AD}[3,11]$. Earlier studies have shown that informant-only perception of cognitive decline may be a better predictor of cognitive decline [12,13] and dementia [14-16] than self-complaint. Furthermore, some studies show that it discriminates preclinical AD from normal aging better than self-informant reports and also displayed higher correlations to cerebrospinal fluid (CSF) core biomarker levels [17], as well as to objective cognitive performance [18-20]. However, perception of decline by an informant does not classify a subject as experiencing SCD and may go self-unrecognized by some subjects, who are therefore not prompted to seek early medical help.

At the dementia stage, the lack of insight of cognitive impairment, or anosognosia, is highly prevalent and increases in parallel to dementia severity [21]. In mild cognitive impairment (MCI), anosognosia is also present in a relevant number of cases [22] and its presence has been related to an increased rate of progression to dementia [23]. A recent study from Alzheimer's Disease Neuroimaging Initiative (ADNI) data gave additional support to the predictive value of impaired self-awareness in the progression from MCI to AD dementia. This study also found an association between impaired self-awareness, brain amyloidosis, and hypometabolism [24]. In presymptomatic stages, the value of impaired self-awareness of cognitive decline to identify subjects at higher risk of progression to symptomatic AD is a topic of growing interest and debate. A recent study performed in the INSIGHT-PreAD cohort concluded that low awareness, defined as the discrepancy between informant and subject reports, but not self-reported difficulties alone, was related to greater amyloid burden and cortical hypometabolism [25]. In contrast, Vannini and colleagues [26] recently reported that cognitively healthy individuals harboring amyloid pathology presented hypernosognosia, defined as worse self-evaluation of their memory ability as compared to objective memory performance. In this scenario, in which some psychometrically normal subjects with cognitive decline may be not self-perceiving or neglecting incipient cognitive difficulties, it may be hypothesized that those having an informant that perceives decline represent a group at increased risk of developing cognitive impairment.

In this study, we aimed at analyzing the cognitive and brain morphometric features of this unaware group, which remain largely unknown. Therefore, we aimed at studying the prevalence of unaware decliners (UD) along with their clinical, cognitive, and structural brain characteristics in a sample of cognitively healthy middle-aged participants from the ALFA population-based research cohort.

\section{METHODS}

\section{Participants}

The ALFA project (ALFA; Clinicaltrials.gov Identifier: NCT01835717) included 2,743 cognitively healthy (exclusion criteria: Mini-Mental State Examination $<26$, Memory Impairment Screen $<6$, semantic fluency $<12$, Clinical Dementia Rating $>0$ ) participants aged between 45 and 74 years with the aim of providing an infrastructure that leverage with different studies and trials to prevent AD (see [27] for details). The study was approved by the Ethics Committee of the "Parc de Salut Mar" (Barcelona, Spain) and conducted in accordance to the directives of the Spanish Law 14/2007, of 3rd of July, on Biomedical Research. All participants signed an informed consent form and had a close relative, who also granted their consent, volunteering to participate in the study to report on the participant's current cognitive and functional status. The present study analyzed data from the 2640 participants that have complete informant ratings available at baseline visit, performed between 2013 and 2014. 
Assessment of perception of cognitive decline and classification of participants

Perception of cognitive decline was explored using the Subjective Cognitive Decline Questionnaire (SCD-Q) [28]. The SCD-Q is a validated tool devised to detect and quantify the perceived subjective cognitive decline that comprises the same set of questions for the subject (SCD-Q MyCog) and the informant (SCD-Q TheirCog). It includes three initial yes/no questions and 24 items inquiring about the presence or absence of difficulties in cognitiverelated activities as compared to the ability estimated 2 years before. Presence or absence of perception of decline was defined using the answer to this initial general question: "Do you perceive memory or cognitive difficulties?" for the subject, and "Do you perceive he/she has cognitive or memory difficulties?" for the informant. According to the answers to these questions participants were classified in: Unaware decliners (UD), if the answer given by the subject was no and the answer given by the informant was yes; $\mathrm{SCD}$, if the subject answered yes regardless informant report; and controls (C), if both the subject and informant answered no. SCD-Q scores were also used to quantify the amount of self-perceived decline and informant perceived decline in each participant.

\section{Cognitive and mood assessment}

Episodic memory was assessed by means the Spanish version of the Memory Binding Test (MBT) [29, 30]. In this test, the examinee should learn two sets of 16 written words that share semantic categories by pairs. Four main variables including free and cued recalls in immediate and delayed (after $25-35 \mathrm{~min}$ ) trials were analyzed: Immediate total paired recall (TPR), immediate total free recall (TFR), delayed total paired recall (TDPR), and delayed total free recall (TDFR). Executive function, visuospatial ability and global intelligence was measured using the Wechsler Adult Intelligence Scale (WAIS) IV Coding, Digit Span, Visual Puzzles, Similarities and Matrix Reasoning subtests [31]. Coding measures, among others, processing speed and attention. The Digit Span subtest evaluates short-term and working memory. Visual Puzzles measures complex visual processing. Matrix Reasoning assesses non-verbal reasoning, and Similarities measures verbal reasoning and abstract thinking. Anxiety and depressive symptoms were evaluated with the Goldberg Anxiety and Depression Scale (GADS) [32], which is composed of two subscales with a maximum score of 9 points each. A global score is also computed by summing up both subscales.

\section{MRI acquisition and preprocessing}

A subgroup of 530 participants underwent a structural magnetic resonance imaging (MRI) study. The percentage of UD $(n=43 ; 8.1 \%)$ and SCD $(n=108$; $20.4 \%)$ did not differed between the scanned and the not scanned group $(p=0.237)$. The subsample of subjects that underwent MRI were in average one year younger $(p<0.05)$ and slightly more educated $(0.3$ years of education, $p<0.05)$ than the group that was not scanned. The percentage of $A P O E$ $\varepsilon 4$ allele carriers is overrepresented in the MRI subsample $(51 \%$ versus $30.7 \%, p<0.001)$. No significant differences in mood or cognitive outcomes were found, except a marginally better performance of scanned individuals in the Similarities subtest $(p<0.05)$. 3D high-resolution T1-weighted images were acquired using a 3T General Electric Discovery scanner with the following acquisition parameters: fast spoiled gradient-echo sequence; voxel size $=1$ $\mathrm{mm}^{3}$ isotropic, Repetition Time [TR] $=6.16 \mathrm{~ms}$, Echo Time $[\mathrm{TE}]=2.33 \mathrm{~ms}$, inversion time $[\mathrm{TI}]=450 \mathrm{~ms}$, matrix size $=256 \times 256 \times 174$, flip angle $=12^{\circ}$ ). Images were segmented into grey matter (GM) tissue using the new segment function implemented in Statistical Parametrical Mapping software (SPM 12, Wellcome Department of Imaging Neuroscience, London, UK), realigned into a common space, and normalized using DARTEL. Jacobian determinants were applied to preserve the local native amount of GM (modulated images). Images were spatially smoothed with a $6 \mathrm{~mm}$ full-width at half maximum Gaussian kernel. Total intracranial volume (TIV) was computed by summing the segmented GM, white matter, and CSF for each individual. Relevant clusters for region-of-interest (ROI) analysis were extracted using MarsBaR (http://marsbar.sourceforge.net).

\section{Statistical analyses}

Mean differences in sociodemographic, cognitive screening, and mood variables among groups were tested using one-way-ANOVA and pairwise post-hoc tests (Tukey). Paired $t$-tests were used to compare subject and informant scores in the SCD-Q. Cognitive performance group differences were explored 
by means of ANCOVAs (using age, years of education, sex, and mood scores as covariates) and pairwise tests. The association between cognitive scores and SCD-Q scores (MyCog and TheirCog) was explored by means partial correlations adjusting for age, years of education and mood scores. Statistical analysis was performed in SPSS IBM v22. All tests were 2-tailed and $p$-values below 0.05 were considered to be statistically significant, except for the ANCOVAs and partial correlations, in which a $p$-value threshold of 0.005 was considered to correct for multiple comparisons (using a Bonferroni-type correction 0.05/10). Voxel-wise analyses were performed using the general linear model as implemented in SPM 12. The segmented, modulated and smoothed GM images were entered in a full-factorial design, with UD, SCD, and $\mathrm{C}$ as a group factor. Pairwise unilateral contrasts were used to explore GM volume differences between groups. In a secondary analysis, a two-factor model with subject's presence/absence and informant's presence/absence of perception of decline was constructed. Age, education, sex, number of $A P O E$ $\varepsilon 4$ alleles, mood scores, and TIV were introduced as nuisance variables. An additive effect of the number of $A P O E \& 4$ alleles was assumed based on previous results in this same sample [33]. An uncorrected $p$ value $(<0.001)$ and a minimum cluster size $(\mathrm{k}=100)$ were used as significance thresholds. The association between GM volumes in clusters of interest and cognitive outcomes was explored by means Spearman correlations. Standardized residuals outputted from general linear models including age, education, sex, number of $A P O E \& 4$ alleles, and mood scores as covariates were used in the correlational analysis.

\section{RESULTS}

$6.6 \%$ of the participants were classified as UD, while prevalence of SCD was $21.5 \%$. SCD subjects were slightly older than $\mathrm{C}$ and had higher levels of subclinical anxiety and depressive symptoms than both $\mathrm{C}$ and UD. Sociodemographic and basic cognition descriptive data for participants are presented in Table 1. Informants' mean age was 52.3 years $(\mathrm{SD}=12.3)$. They were mainly spouses of participants $(67.2 \%)$, adult children (13.0\%), or siblings (9.4\%). The frequency of contact was in most cases daily $(79.9 \%)$ or once a week $(16.4 \%)$. Groups did not differ in informant's age, type of relationship, or frequency of contact. There was a higher percentage of women acting as informants in the UD (61.8\%, $p=0.02)$ than in the C (51.0\%) and the SCD (50.2\%) groups, together with a higher percentage of men in the UD group.

As expected, there were significant differences among groups in both self- and informant-reported SCD-Q scores ( $p<0.001$; Table 1 and Fig. 1). Specifically, SCD-Q MyCog scores were the highest in the SCD group and in the UD group were higher than in C. The lowest SCD-Q TheirCog scores were found in the $\mathrm{C}$ group while the UD group displayed the highest scores. There were also differences between self and informant ratings in the within group comparisons: In the UD group, informants reported a higher degree of complains than the UD subjects $(p<0.001)$. The

Table 1

Sociodemographic and basic cognitive descriptive data

\begin{tabular}{lccc}
\hline & $\mathrm{C}$ & $\mathrm{UD}$ & $\mathrm{SCD}$ \\
\hline $\mathrm{N}$ & 1899 & 173 & 568 \\
Age M(SD) & $55.31(6.59)$ & $56.46(6.89)^{\mathrm{b}}$ & $57.14(6.86)$ \\
Education M (SD) & $13.51(3.50)$ & $12.38(3.51)^{\mathrm{a}}$ & $13.14(3.50)$ \\
MMSE M (SD) & $29.09(1.04)$ & $29.03(1.00)$ & $28.82(1.18)$ \\
GADS Total M (SD) & $0.61(1.35)$ & $0.62(1.24)^{\mathrm{b}}$ & $1.29(2.03)^{\mathrm{c}}$ \\
SCD-Q MyCog & $4.18(3.95)$ & $6.09(4.70)^{\mathrm{ab}}$ & $12.00(5.86)^{\mathrm{c}}$ \\
SCD-Q TheirCog & $2.22(2.22)$ & $8.76(4.61)^{\mathrm{ab}}$ & $5.08(4.76)^{\mathrm{c}}$ \\
Females (\%) & $64.1 \%$ & $48.0 \%{ }^{\mathrm{ab}}$ & $65.0 \%$ \\
$\varepsilon^{4}$ Carriers (\%) & $34.6 \%$ & $37.6 \%$ & $34.3 \%$ \\
\hline
\end{tabular}

$\mathrm{C}$, control; UD, unaware decliners; SCD, subjective cognitive decline; MMSE, Mini-Mental State Examination; GADS, Goldberg Anxiety and Depression Scale; SCD-Q, SCD Questionnaire; ${ }^{\mathrm{a}} p<0.05$ UD versus $C ;{ }^{\mathrm{b}} p<0.05 \mathrm{UD}$ versus SCD; ${ }^{\mathrm{c}} p<0.05 \mathrm{SCD}$ versus $C$.

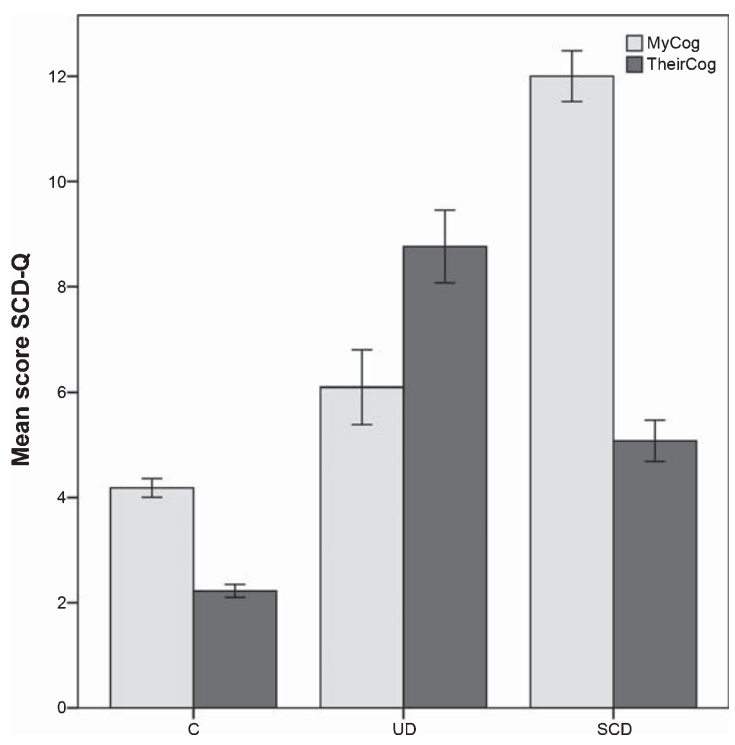

Fig. 1. SCD-Q results. Mean and standard errors are depicted. C, controls; UD, unaware decliner; $\mathrm{SCD}$, subjective cognitive decline. 
opposite pattern was found for $\mathrm{C}$ and SCD groups $(p<0.001)$. These data are shown in Fig. 1.

Cognitive performance descriptive data are shown in Table 2 along with the results of inferential tests adjusting for confounders and correcting for multiple comparisons $(p<0.005)$. UD performed worse than $\mathrm{C}$ in the free recall trials of the MBT. The SCD group displayed a consistent lower performance than $\mathrm{C}$ in all episodic memory measures and also in the Coding subtest of the WAIS-IV. No significant differences were observed between UD and SCD.

We found weak $(r<-0.1)$ but significant, negative, associations between SCD-Q scores and cognitive outcomes in UD and SCD participants. Partial correlations for the self-reported MyCog score were significant $(p<0.005)$ for both the immediate and delayed free recall of the MBT $(r=-0.059$ and

Table 2

Cognitive outcomes descriptive data

\begin{tabular}{|c|c|c|c|}
\hline & $\mathrm{C}$ & UD & SCD \\
\hline MBT-TPR & $24.42(4.22)$ & $23.19(3.37)$ & $23.28(4.77)^{\mathrm{b}}$ \\
\hline MBT-TFR & $16.94(4.93)$ & $15.17(4.34)^{\mathrm{a}}$ & $15.53(5.09)^{b}$ \\
\hline MBT-TDFR & $17.32(5.0)$ & $15.66(4.52)^{\mathrm{a}}$ & $15.80(5.43)^{b}$ \\
\hline MBT-TDPR & $24.26(4.3)$ & $22.94(4.40)$ & $23.07(4.94)^{b}$ \\
\hline WAIS-Coding & $67.09(14.54)$ & $62.77(14.63)$ & $62.93(14.75)^{\mathrm{b}}$ \\
\hline $\begin{array}{l}\text { WAIS-Visual } \\
\text { Puzzles }\end{array}$ & $13.57(4.27)$ & $13.42(4.32)$ & $12.61(4.07)$ \\
\hline $\begin{array}{l}\text { WAIS-Digit } \\
\text { Span Total }\end{array}$ & $24.99(5.15)$ & $24.03(4.98)$ & $24.30(5.45)$ \\
\hline $\begin{array}{l}\text { WAIS-Matrix } \\
\text { Reasoning }\end{array}$ & $16.78(4.37)$ & $16.73(4.05)$ & $15.92(4.52)$ \\
\hline WAIS- & $22.40(4.61)$ & $21.41(4.90)$ & $21.55(4.78)$ \\
\hline
\end{tabular}

Similarities

C, controls; UD, unaware decliners; SCD, subjective cognitive decline, MBT, Memory Binding Test; TPR, Immediate total paired recall; TFR, immediate total free recall; TDFR, delayed total free recall; TDPR, delayed total paired recall; WAIS, Wechsler Adult Intelligence Scale; significant pairwise differences in ANCOVA adjusted for age, education, sex and mood scores are shown. $p$ value adjusted for multiple comparisons ${ }^{\mathrm{a}} p<0.005$ UD versus $\mathrm{C}$; ${ }^{\mathrm{b}} p<0.005$ SCD versus C. $r=-0.072$ ), while $\mathrm{SuCog}$ scores presented significant associations with free recall (TFR, $r=-0.075$; TDFR, $r=-0.086$ ), cued recall trials (TPR, $r=-0.058$; TDPR, $r=-0.057)$, and WAIS Coding $(r=-0.055)$.

Voxel-based morphometry (VBM) analysis revealed a pattern of increased GM volume in the UD group as compared to the $\mathrm{C}$ one. These changes were located in right medial frontal areas and right insula (see Fig. 2 and Table 3). In comparison to the SCD group, UD subjects showed lower GM cerebellar volumes (vermis lobule IV and V, see Table 3). No significant differences in the opposite directions were observed for these comparisons, neither for the SCD versus the UD group.

Next, we tested whether having a positive informant report of cognitive change predicted GM volume, regardless of the presence or absence of self-perceived decline. This analysis showed a significant main effect for a positive informant report, in which the left posterior hippocampus and cerebellum displayed lower GM volumes (Fig. 3, Table 3). To evaluate if there was a cognitive expression of such finding, we created an ROI by extracting the hippocampal cluster to explore the association with the memory variable that had shown the largest effect size among groups, i.e. total delayed free recall (TDFR). In the whole group, no correlation was found between TDFR and left hippocampal GM values (adjusted by confounders, age, sex, education, number of $A P O E \varepsilon 4$ alleles, and GADS score; rho $=0.03$; $p=0.44)$. However, when this analysis was repeated within groups, a significant association arose in the UD group (rho $=0.46, p=0.002$, Fig. 3B lower right panel), but not in the $\mathrm{C}$ and $\mathrm{SCD}$ groups (rho $=-0.05$, $p=0.33 ; r=0.07, p=0.82$, Fig. 3B upper and lower left panels). There was not either an association between TDFR and hippocampal GM volume when the analysis was restricted to the SCD subjects that

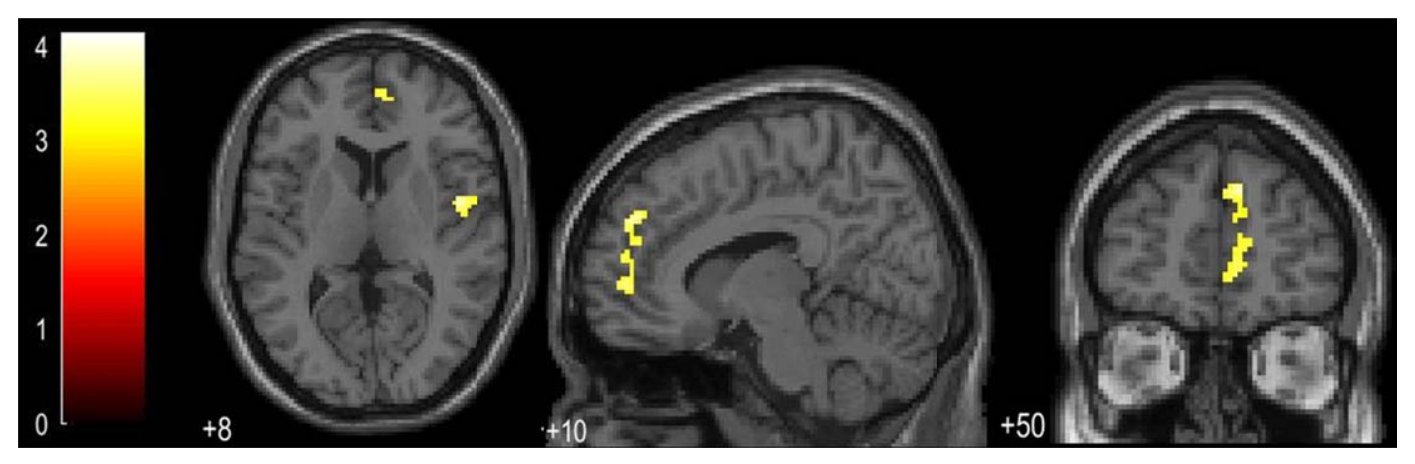

Fig. 2. Regions of GM volume increments in the UD group as compared to the $\mathrm{C}$ group. 
Table 3

Brain regions showing statistically significant GM volumetric change

\begin{tabular}{|c|c|c|c|c|c|c|c|}
\hline \multirow[t]{2}{*}{ Contrast } & \multirow[t]{2}{*}{ Distribution } & \multirow[t]{2}{*}{ Label } & \multicolumn{3}{|c|}{ MNI coordinates } & \multirow{2}{*}{$\begin{array}{l}\text { Cluster } \\
\text { Size }\end{array}$} & \multirow{2}{*}{$\begin{array}{l}\text { Peak } \\
\text { Z-score }\end{array}$} \\
\hline & & & $\mathrm{x}$ & $\mathrm{y}$ & $\mathrm{Z}$ & & \\
\hline \multirow[t]{2}{*}{$\mathrm{UD}>\mathrm{C}$} & Cluster 1 & $\begin{array}{l}\text { Right Frontal Medial } \\
\text { Orbital } \\
\text { Right Anterior Cingulum }\end{array}$ & 9 & 50 & 33 & 401 & 4.24 \\
\hline & Cluster 2 & Right Insula & 47 & -2 & 8 & 211 & 3.95 \\
\hline $\mathrm{SCD}>\mathrm{UD}$ & Cluster 1 & $\begin{array}{l}\text { Vermis } 4-5 \\
\text { Vermis } 3\end{array}$ & 6 & -48 & -18 & 102 & 3.44 \\
\hline \multirow{3}{*}{$\begin{array}{l}\text { Main effect of } \\
\text { informant reported } \\
\text { decline (lower GM) }\end{array}$} & Cluster 1 & Left Hippocampus & -32 & -30 & -3 & 189 & 4.28 \\
\hline & Cluster 2 & $\begin{array}{l}\text { Vermis } 8 \\
\text { Left Cerebellum } 8\end{array}$ & 2 & -75 & -27 & 146 & 3.81 \\
\hline & Cluster 3 & $\begin{array}{l}\text { Left Cerebellum 7b } \\
\text { Left Cerebellum Crus } 2\end{array}$ & -32 & -80 & -38 & 433 & 3.64 \\
\hline
\end{tabular}

Automated Anatomical Labeling (AAL) labels are used; MNI, Montreal Neurological Institute; UD, unaware decliner; C, controls; SCD, subjective cognitive decline.

had informant positive report of decline (rho $=0.03$, $p=0.85, n=39$ ).

\section{DISCUSSION}

Our study shows that, even though the prevalence of middle aged psychometrically normal subjects unaware of cognitive decline (UD) is low compared with those of SCD, they present distinct cognitive performance and structural MRI features as compared to controls, which consists in a specific impairment in free recall tests, together with a brain morphologic pattern of increments in GM volumes in medial frontal areas and insula. Moreover, the presence of a positive informant report, irrespective of the self-awareness status, is associated with lower left posterior hippocampal GM volume.

Prevalence of UD in our study is twice the reported by Gifford and colleagues [12,14] in older subjects enrolled in the National Alzheimer's Coordinating Center. This discrepancy could be related with sample recruitment (clinical center versus research setting, respectively) and how UD is defined. In our study, the SCD-Q was used to define the absence or presence of perception of decline, while in the cited report the clinician reported absence or presence of perception of cognitive decline after interviewing the participant and the informant. An additional explanation for this difference may be related with the sample characteristics.

Noteworthy, we found a higher number of males in the UD group, together with a higher number of females acting as informants in this group. Besides, although small, a significant difference in years of education was also observed, being the UD group less educated than the $\mathrm{C}$ and SCD ones. Taken together, these results suggest that sociodemographic characteristics play a relevant role in both the insight and the reporting of self- and relative-related cognitive difficulties.

With regard to cognition, UD subjects showed worse memory performance than controls in the free recall of the MBT after adjusting for confounders. Associations between informant ratings (SCD-Q TheirCog score) and cognitive scores were also more robustly related to actual cognitive performance than self-reported ones. These findings give additional credit to the value of informant's report of decline, even in absence of self-perception of decline, to capture subtle cognitive changes. Previous studies using a similar grouping strategy [12], or grouping by degree of awareness [25], did not find any cross-sectional difference in memory performance using either a logical memory task or the FCSRT, respectively. In the present study we used the MBT, which is a more challenging test that was devised to capture subtle memory differences and to overcome the ceiling effect found with routine clinical memory assessments in cognitively healthy individuals [34]. By using this novel test, we were able to capture slight group differences. Similar to other memory tests, the MBT provides both free and cued recall measures. While in symptomatic AD total recall, which captures the failure to benefit from cueing, constitutes the specific AD signature of memory impairment [35-38], free recall seems to be the most sensitive measure in the prediction of $\mathrm{AD}$ dementia [39, 40]. Our results suggest that free recall could also be the most 


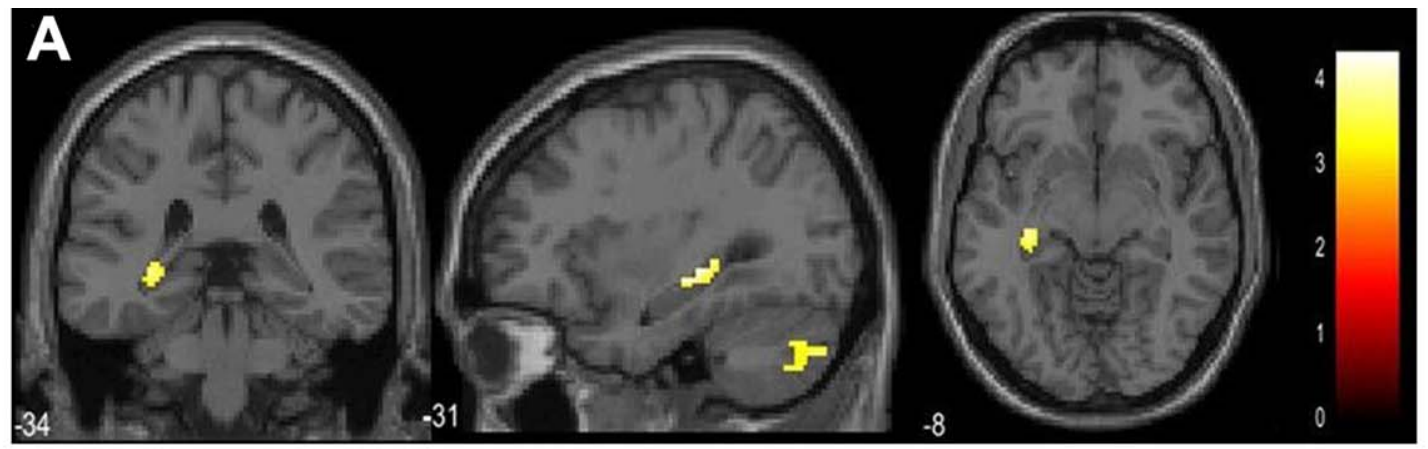

B
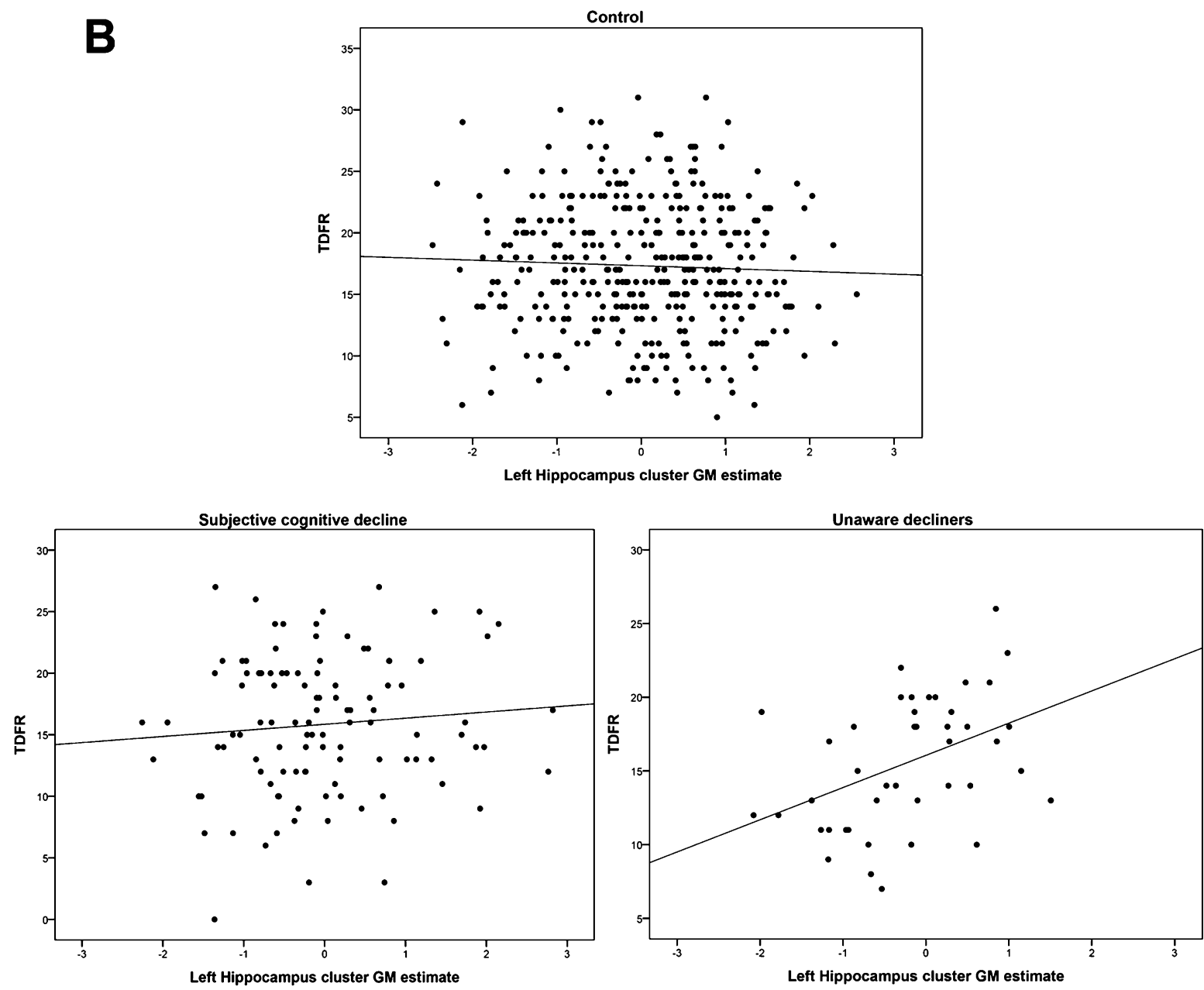

Fig. 3. Main effect of positive informant report of decline in decrements of GM volumes (A) and within group associations between memory and GM in the hippocampal cluster (B).

sensitive measure to capture subtle memory changes as detected by an external observer in absence of insight of the participant.

With regard to the neuroimaging study, we found that having a positive informant report of cognitive change, irrespective of the presence of selfawareness, was related to a decrease in GM volume in the left posterior hippocampus and cerebellum. Furthermore, GM volume in the hippocampal cluster was correlated with the delayed free recall score 
in the UD group. This association was not observed in the SCD subjects with confirmation of decline by the informant or in the control sample. Taken together, these results suggest a specific interplay between the unawareness of cognitive decline and processes of hippocampal atrophy that relates to memory decrease. Further studies are necessary to explore this hypothesis.

UD displayed increased GM volume in right medial prefrontal areas and the insula as compared to controls. These areas, mainly the medial prefrontal cortex (MPFC), have been related to the processing of self-referential information [41]. Functional MRI studies highlighted the relevance of these areas in self-awareness in symptomatic AD stages. MCI patients that display less insight show less activation than controls in the MPFC and the posterior cingulate cortex during a self-appraisal task [42], and altered MPFC functional connectivity with other cortical midline areas was also related to variability in memory self-appraisal accuracy in MCI and early AD [43]. Previous morphometric studies in mild AD dementia, found that anosognosia of memory deficits was correlated with decreased volume in the superior frontal lobe [44]. In healthy subjects, smaller volumes in the MPFC and insula have been related to higher alexithymia traits, which is a difficulty recognizing and describing the own feelings [45, 46], and that decreased right insula volume was associated with lower memory awareness [47]. Our findings in unimpaired subjects with low awareness are in contrast with previous evidence pointing out to a positive relationship between brain volume and self-appraisal. This divergence could be interpreted in at least two ways: Firstly, volumetric increments may be reflecting subject personalityrelated brain differences. For example, neuroticism, which in its simplest definition is the tendency to experience negative emotions, has been associated with reduced volume in dorsomedial prefrontal cortex and increased volume in the mid-cingulate gyrus [48]. It is plausible that the judgment of our own cognitive status may be influenced by personality traits with specific brain structural correlates. Secondly, taking into account that UD performed worse than controls in cognitive tasks and that non-linear brain volumetric changes, with initial increments in GM volume that decrease later on, have been described in preclinical AD [49], GM increments may relate to an initial form of unawareness of decline (that is, incipient anosognosia). This latter hypothesis implies a higher risk of future cognitive decline in an additional group of subjects on top of the well-described SCD group.

The relationship between subjective perception of decline and anosognosia in preclinical $\mathrm{AD}$ is a recent matter of debate. In a set of papers on the topic using different neuroimaging approaches in healthy controls, preclinical AD, and MCI, Vannini and colleagues draw a picture in which increments in subjective cognitive complains (hypernosognosia) would appear early at the preclinical stage related to decreased brain metabolism and presence of amyloid burden $[26,50,51]$. This pattern of high-awareness would later flip into anosognosia as brain pathology progress in the MCI stage, in which unawareness has been related to greater amyloid- $\beta$ load, glucose hypometabolism in areas representing the default mode network, and higher progression to AD dementia [24]. Our results contrast with their findings in preclinical AD [26] but are consistent with the findings reported by Cacciamani et al. [25], who reported higher AD pathology in subjects with reduced awareness. These divergent evidences may be reflecting the existence of two different groups of subjects at risk of future cognitive impairment. While SCD may represent the most frequent feature in subjects preceding and progressing toward cognitive impairment, UDs may express early anosognosia accounting for a smaller group that may also be at risk for cognitive impairment. In addition, unawareness may delay seeking for medical help and limit their enrollment in secondary prevention clinical trials. Our results highlight the relevance of obtaining informant reports in studies in individuals at risk for $\mathrm{AD}$ and the interest of performing discrepancy analysis between these and the participants' reports. Unraveling the clinical characteristics of participants at risk for cognitive impairment is of key importance for the design of prevention strategies. Further longitudinal studies are needed to ascertain the relevance of UD for predicting cognitive decline of early impaired.

The present study is not free of limitations that are primarily as follows: The absence of information on AD biomarkers in this sample prevents us from exploring the relationship between unawareness and biological surrogates of AD pathology. The cross-sectional nature of our study does not permit to address the hypothesis of higher risk of cognitive decline in the UD group. Both of these limitations will be overcome with longitudinal data recording that is currently underway. Another limitation relates to uncontrolled informant bias. Presence of 
psychoaffective symptoms, beliefs and fear of developing dementia, as well as personality traits, may affect informant reports and were not assessed in the current study.

In summary, we found that middle-aged psychometrically normal subjects unaware of informantreported cognitive decline display lower memory scores that are related to hippocampal volume and additional brain differences in areas involved in processing self-referential information. Our results support the usefulness of informant reports and suggest that unaware decliners may represent a distinct clinical group at risk of cognitive impairment. Longitudinal studies will be of value to understand the rate of objective cognitive decline of this proposed new group of healthy participants.

\section{ACKNOWLEDGMENTS}

The research leading to these results has received funding from "la Caixa" Foundation. Additional funding was obtained from Fondo de Investigación Sanitaria (FIS) under grant PI12/00326. Juan D. Gispert holds a 'Ramón y Cajal' fellowship (RYC2013-13054). CM is supported by the Spanish Ministry of Economy and Competitiveness (grant $\mathrm{n}^{\circ}$ IEDI-2016-00690). This publication is part of the ALFA study (ALzheimer and FAmilies). The authors would like to express their most sincere gratitude to the ALFA project participants, without whom this research would have not been possible.

Collaborators of the ALFA study are: Jordi Camí, Grégory Operto, Stavros Skouras, Karine Fauria, Anna Brugulat-Serrat, Gemma Salvadó, Albina Polo, Cristina Mustata, Laia Tenas, Paula Marne, Xavi Gotsens, Tania Menchón, Anna Soteras, Laura Hernandez, Ruth Dominguez, Sandra Pradas, Gema Huesa, Marc Vilanova, Sabrina Segundo, Jordi Huguet.

Authors' disclosures available online (https:// www.j-alz.com/manuscript-disclosures/18-0378r1).

\section{REFERENCES}

[1] Dubois B, Hampel H, Feldman HH, Scheltens P, Aisen P, Andrieu S, Bakardjian H, Benali H, Bertram L, Blennow K, Broich K, Cavedo E, Crutch S, Dartigues J-F, Duyckaerts C, Epelbaum S, Frisoni GB, Gauthier S, Genthon R, Gouw AA, Habert M-O, Holtzman DM, Kivipelto M, Lista S, Molinuevo J-L, O'Bryant SE, Rabinovici GD, Rowe C, Salloway S, Schneider LS, Sperling R, Teichmann M, Carrillo MC, Cummings J, Jack CR, Proceedings of the Meeting of the International Working Group (IWG) and the American Alzheimer's Association on "The Preclinical State of AD"; July 23, 2015; Washington DC, USA (2016) Preclinical Alzheimer's disease: Definition, natural history, and diagnostic criteria. Alzheimers Dement 12, 292-323.

[2] Jack CR, Bennett DA, Blennow K, Carrillo MC, Dunn B, Haeberlein SB, Holtzman DM, Jagust W, Jessen F, Karlawish J, Liu E, Molinuevo JL, Montine T, Phelps C, Rankin KP, Rowe CC, Scheltens P, Siemers E, Snyder HM, Sperling R, Elliott C, Masliah E, Ryan L, Silverberg N (2018) NIA-AA Research Framework: Toward a biological definition of Alzheimer's disease. Alzheimers Dement 14, 535-562.

[3] Jessen F, Amariglio RE, van Boxtel M, Breteler M, Ceccaldi M, Chételat G, Dubois B, Dufouil C, Ellis KA, van der Flier WM, Glodzik L, van Harten AC, de Leon MJ, McHugh P, Mielke MM, Molinuevo JL, Mosconi L, Osorio RS, Perrotin A, Petersen RC, Rabin LA, Rami L, Reisberg B, Rentz DM, Sachdev PS, de la Sayette V, Saykin AJ, Scheltens P, Shulman MB, Slavin MJ, Sperling RA, Stewart R, Uspenskaya O, Vellas B, Visser PJ, Wagner M, Subjective Cognitive Decline Initiative (SCD-I) Working Group (2014) A conceptual framework for research on subjective cognitive decline in preclinical Alzheimer's disease. Alzheimers Dement 10, 844-852.

[4] Rabin LA, Smart CM, Amariglio RE (2017) Subjective cognitive decline in preclinical Alzheimer's disease. Апnи Rev Clin Psychol 13, 369-396.

[5] Mitchell AJ, Beaumont H, Ferguson D, Yadegarfar M, Stubbs B (2014) Risk of dementia and mild cognitive impairment in older people with subjective memory complaints: Meta-analysis. Acta Psychiatr Scand 130, 439-451.

[6] Eckerström M, Göthlin M, Rolstad S, Hessen E, Eckerström C, Nordlund A, Johansson B, Svensson J, Jonsson M, Sacuiu S, Wallin A (2017) Longitudinal evaluation of criteria for subjective cognitive decline and preclinical Alzheimer's disease in a memory clinic sample. Alzheimers Dement (Amst) 8, 96-107.

[7] Snitz BE, Wang T, Cloonan YK, Jacobsen E, Chang C-CH, Hughes TF, Kamboh MI, Ganguli M (2018) Risk of progression from subjective cognitive decline to mild cognitive impairment: The role of study setting. Alzheimers Dement 14, 734-742.

[8] Ramakers IHGB, Visser PJ, Bittermann AJN, Ponds RWHM, van Boxtel MPJ, Verhey FRJ (2009) Characteristics of help-seeking behaviour in subjects with subjective memory complaints at a memory clinic: A case-control study. Int J Geriatr Psychiatry 24, 190-196.

[9] Rabin LA, Wang C, Katz MJ, Derby CA, Buschke H, Lipton RB (2012) Predicting Alzheimer's disease: Neuropsychological tests, self-reports, and informant reports of cognitive difficulties. J Am Geriatr Soc 60, 1128-1134.

[10] Gifford KA, Liu D, Damon SM, Chapman WG, Romano Iii RR, Samuels LR, Lu Z, Jefferson AL, Alzheimer's Disease Neuroimaging Initiative (2015) Subjective memory complaint only relates to verbal episodic memory performance in mild cognitive impairment. J Alzheimers Dis $\mathbf{4 4}$, 309-318.

[11] Molinuevo JL, Rabin LA, Amariglio R, Buckley R, Dubois B, Ellis KA, Ewers M, Hampel H, Klöppel S, Rami L, Reisberg B, Saykin AJ, Sikkes S, Smart CM, Snitz BE, Sperling R, van der Flier WM, Wagner M, Jessen F (2017) Implementation of subjective cognitive decline criteria in research studies. Alzheimers Dement 13, 296-311. 
[12] Gifford KA, Liu D, Carmona H, Lu Z, Romano R, Tripodis Y, Martin B, Kowall N, Jefferson AL (2015) Inclusion of an informant yields strong associations between cognitive complaint and longitudinal cognitive outcomes in non-demented elders. J Alzheimers Dis 43, 121-132.

[13] Jorm AF, Christensen H, Henderson AS, Jacomb PA, Korten AE, Mackinnon A (1996) Informant ratings of cognitive decline of elderly people: Relationship to longitudinal change on cognitive tests. Age Ageing 25, 125-129.

[14] Gifford KA, Liu D, Lu Z, Tripodis Y, Cantwell N, Palmisano J, Kowall N, Jefferson AL (2014) The source of cognitive complaints differentially predicts diagnostic conversion in non-demented older adults. Alzheimers Dement 10, 319327.

[15] Carr DB, Gray S, Baty J, Morris JC (2000) The value of informant versus individual's complaints of memory impairment in early dementia. Neurology 55, 1724-1726.

[16] Tierney MC, Szalai JP, Snow WG, Fisher RH (1996) The prediction of Alzheimer disease. The role of patient and informant perceptions of cognitive deficits. Arch Neurol 53, 423-427.

[17] Valech N, Mollica MA, Olives J, Tort A, Fortea J, Lleo A, Belén SS, Molinuevo JL, Rami L (2015) Informant's perception of subjective cognitive decline helps to discriminate preclinical Alzheimer's disease from normal aging. $J$ Alzheimers Dis 48, S87-S98.

[18] Rami L, Solé-Padullés C, Fortea J, Bosch B, Lladó A, Antonell A, Olives J, Castellví M, Bartres-Faz D, SánchezValle R, Molinuevo JL, Sole-Padulles C, Llado A, Castellvi M, Sanchez-Valle R (2012) Applying the new research diagnostic criteria: MRI findings and neuropsychological correlations of prodromal AD. Int J Geriatr Psychiatry 27, 127-134.

[19] Gavett R, Dunn JE, Stoddard A, Harty B, Weintraub S (2011) The Cognitive Change in Women study (CCW): Informant ratings of cognitive change but not self-ratings are associated with neuropsychological performance over 3 years. Alzheimer Dis Assoc Disord 25, 305-311.

[20] Slavin MJ, Brodaty H, Kochan NA, Crawford JD, Trollor JN, Draper B, Sachdev PS (2010) Prevalence and predictors of "subjective cognitive complaints" in the Sydney Memory and Ageing Study. TL - 18. Am J Geriatr Psychiatry 18, 701-710.

[21] Starkstein SE (2014) Anosognosia in Alzheimer's disease: Diagnosis, frequency, mechanism and clinical correlates. Cortex 61, 64-73.

[22] Roberts JL, Clare L, Woods RT (2009) Subjective memory complaints and awareness of memory functioning in mild cognitive impairment: A systematic review. Dement Geriatr Cogn Disord 28, 95-109.

[23] Tabert MH, Albert SM, Borukhova-Milov L, Camacho Y, Pelton G, Liu X, Stern Y, Devanand DP (2002) Functional deficits in patients with mild cognitive impairment: Prediction of AD. Neurology 58, 758-764.

[24] Therriault J, Ng KP, Pascoal TA, Mathotaarachchi S, Kang MS, Struyfs H, Shin M, Benedet AL, Walpola IC, Nair V, Gauthier S, Rosa-Neto P, Alzheimer's Disease Neuroimaging Initiative (2018) Anosognosia predicts default mode network hypometabolism and clinical progression to dementia. Neurology 90, e932-e939.

[25] Cacciamani F, Tandetnik C, Gagliardi G, Bertin H, Habert M-O, Hampel H, Boukadida L, Révillon M, Epelbaum S, Dubois B, INSIGHT-PreAD study group (2017) Low cognitive awareness, but not complaint, is a good marker of preclinical Alzheimer's disease. J Alzheimers Dis 59, 753762.

[26] Vannini P, Amariglio R, Hanseeuw B, Johnson KA, McLaren DG, Chhatwal J, Pascual-Leone A, Rentz D, Sperling RA (2017) Memory self-awareness in the preclinical and prodromal stages of Alzheimer's disease. Neuropsychologia 99, 343-349.

[27] Molinuevo JL, Gramunt N, Gispert JD, Fauria K, Esteller M, Minguillon C, Sánchez-Benavides G, Huesa G, Morán S, Dal-Ré R, Camí J (2016) The ALFA project: A research platform to identify early pathophysiological features of Alzheimer's disease. Alzheimers Dement (N Y) 2, 82-92.

[28] Rami L, Mollica MA, Garcfa-Sanchez C, Saldafia J, Sanchez B, Sala I, Valls-Pedret C, Castellvi M, Olives J, Molinuevo JL (2014) The subjective cognitive decline questionnaire (SCD-Q): A validation study. J Alzheimers Dis 41, 453-466.

[29] Buschke H (2014) Rationale of the Memory Binding Test. In Dementia and Memory, Nilsson L, Ohta N, eds. Psychology Press, Hove, East Sussex, pp. 55-61.

[30] Gramunt N, Sánchez-Benavides G, Buschke H, DiéguezVide F, Peña-Casanova J, Masramon X, Fauria K, Gispert JD, Molinuevo JL (2016) The Memory Binding Test: Development of two alternate forms into Spanish and Catalan. $J$ Alzheimers Dis 52, 283-293.

[31] Wechsler D (2012) Escala de Inteligencia Wechsler para adultos IV (Spanish version), Pearson, Madrid.

[32] Goldberg D, Bridges K, Duncan-Jones P, Grayson D (1988) Detecting anxiety and depression in general medical settings. BMJ 297, 897-899.

[33] Cacciaglia R, Molinuevo JL, Falcón C, Brugulat-Serrat A, Sánchez-Benavides G, Gramunt N, Esteller M, Morán S, Minguillón C, Fauria K, Gispert JD (2018) Effects of APOE- $\varepsilon 4$ allele load on brain morphology in a cohort of middle-aged healthy individuals with enriched genetic risk for Alzheimer's disease. Alzheimers Dement. doi: 10.1016/j.jalz.2018.01.016

[34] Gramunt N, Sánchez-Benavides G, Buschke H, Lipton RB, Masramon X, Gispert JD, Peña-Casanova J, Fauria K, Molinuevo JL (2016) Psychometric properties of the Memory Binding Test: Test-retest reliability and convergent validity. J Alzheimers Dis 50, 999-1010.

[35] Sarazin M, Berr C, De Rotrou J, Fabrigoule C, Pasquier F, Legrain S, Michel B, Puel M, Volteau M, Touchon J, Verny M, Dubois B (2007) Amnestic syndrome of the medial temporal type identifies prodromal AD: A longitudinal study. Neurology 69, 1859-1867.

[36] Dubois B, Feldman HH, Jacova C, Hampel H, Molinuevo JL, Blennow K, DeKosky ST, Gauthier S, Selkoe D, Bateman R, Cappa S, Crutch S, Engelborghs S, Frisoni GB, Fox NC, Galasko D, Habert M-O, Jicha GA, Nordberg A, Pasquier F, Rabinovici G, Robert P, Rowe C, Salloway S, Sarazin M, Epelbaum S, de Souza LC, Vellas B, Visser PJ, Schneider L, Stern Y, Scheltens P, Cummings JL (2014) Advancing research diagnostic criteria for Alzheimer's disease: The IWG-2 criteria. Lancet Neurol 13, 614-629.

[37] Saka E, Mihci E, Topcuoglu MA, Balkan S (2006) Enhanced cued recall has a high utility as a screening test in the diagnosis of Alzheimer's disease and mild cognitive impairment in Turkish people. Arch Clin Neuropsychol 21, 745-751.

[38] Grober E, Kawas C (1997) Learning and retention in preclinical and early Alzheimer's disease. Psychol Aging 12, 183-188. 
[39] Auriacombe S, Helmer C, Amieva H, Berr C, Dubois B, Dartigues J-FF (2010) Validity of the free and cued selective reminding test in predicting dementia: The $3 \mathrm{C}$ study. Neurology 74, 1760-1767.

[40] Grober E, Sanders AE, Hall C, Lipton RB (2010) Free and cued selective reminding identifies very mild dementia in primary care. Alzheimer Dis Assoc Disord 24, 284-290.

[41] Northoff G, Heinzel A, de Greck M, Bermpohl F, Dobrowolny H, Panksepp J (2006) Self-referential processing in our brain-A meta-analysis of imaging studies on the self. Neuroimage 31, 440-457.

[42] Ries ML, Jabbar BM, Schmitz TW, Trivedi MA, Gleason CE, Carlsson CM, Rowley HA, Asthana S, Johnson SC (2007) Anosognosia in mild cognitive impairment: Relationship to activation of cortical midline structures involved in self-appraisal. J Int Neuropsychol Soc 13, 450-461.

[43] Ries ML, McLaren DG, Bendlin BB, GuofanXu, Rowley HA, Birn R, Kastman EK, Sager MA, Asthana S, Johnson SC (2012) Medial prefrontal functional connectivity-Relation to memory self-appraisal accuracy in older adults with and without memory disorders. $\mathrm{Neu}$ ropsychologia 50, 603-611.

[44] Fujimoto H, Matsuoka T, Kato Y, Shibata K, Nakamura K, Yamada K, Narumoto J (2017) Brain regions associated with anosognosia for memory disturbance in Alzheimer's disease: A magnetic resonance imaging study. Neuropsychiatr Dis Treat 13, 1753-1759.

[45] Gündel H, López-Sala A, Ceballos-Baumann AO, Deus J, Cardoner N, Marten-Mittag B, Soriano-Mas C, Pujol J (2004) Alexithymia correlates with the size of the right anterior cingulate. Psychosom Med 66, 132-140.
[46] Borsci G, Boccardi M, Rossi R, Rossi G, Perez J, Bonetti M, Frisoni GB (2009) Alexithymia in healthy women: A brain morphology study. J Affect Disord 114, 208-215.

[47] Cosentino S, Brickman AM, Griffith E, Habeck C, Cines S, Farrell M, Shaked D, Huey ED, Briner T, Stern Y (2015) The right insula contributes to memory awareness in cognitively diverse older adults. Neuropsychologia 75, 163-169.

[48] DeYoung CG, Hirsh JB, Shane MS, Papademetris X, Rajeevan N, Gray JR (2010) Testing predictions from personality neuroscience. Brain structure and the big five. Psychol Sci 21, 820-828.

[49] Gispert JD, Rami L, Sánchez-Benavides G, Falcon C, Tucholka A, Rojas S, Molinuevo JL (2015) Nonlinear cerebral atrophy patterns across the Alzheimer's disease continuum: Impact of APOE4 genotype. Neurobiol Aging 36, 2687-2701.

[50] Vannini P, Hanseeuw B, Munro CE, Amariglio RE, Marshall GA, Rentz DM, Pascual-Leone A, Johnson KA, Sperling RA (2017) Anosognosia for memory deficits in mild cognitive impairment: Insight into the neural mechanism using functional and molecular imaging. Neuroimage Clin 15, 408-414.

[51] Vannini P, Hanseeuw B, Munro CE, Amariglio RE, Marshall GA, Rentz DM, Pascual-Leone A, Johnson KA, Sperling RA (2017) Hippocampal hypometabolism in older adults with memory complaints and increased amyloid burden. Neurology 88, 1759-1767. 